Proceedings of the New Zealand Grassland Association 46: 65-69 (1985)

\title{
GRAZING INTENSITY AND SOIL NITROGEN ACCUMULATION
}

J.H. HOGLUND

Grasslands Division, DSIR, Lincoln

\begin{abstract}
The balance between the litter and animal excreta pathways was varied by imposing a range of sheep grazing intensities on a dryland ryegrass-white clover pasture for 3 years. In contrast to laxly grazed treatments, hard grazed treatments lost soil carbon and nitrogen. Greatest overall losses occurred in the driest year, and lowest losses occurred in years of greatest pasture growth. The importance of allowing some litter cycling, by avoiding continual hard grazing is discussed.
\end{abstract}

Keywords: N-fixation, soil nitrogen, grazing, carbon, balance, litter, pasture.

\section{INTRODUCTION}

Many agricultural systems rely in part on exploitation of previousiy accumuiaied soil nutrient pools. For example, pasture development on forested sites relies, in the first instance, on the reservoir of nutrients in the organic matter and ash which had slowly accumulated under the previous vegetation. In this context, intensive animal grazing is often seen as desirable, in that it accelerates the breakdown of organic matter and concentrates nutrients in urine patches, thereby promoting growth of high fertility demanding plant species. Similarly, cropping of land previously used for pasture, provides an apparently cheap source of nutrients during initial years. These principles have long been recognised and some ancient cultures are based on 'shifting agriculture', whereby intensive utilisation is alternated with long periods of conservation.

Soil nitrogen is particularly sensitive because of it's high rate of turnover in agroecosystems, and high potential for loss, particularly as a consequence of intensive animal grazing. The grazing animal concentrates nitrogen in urine and in so doing separates it from the stabilising influence of carbon and thereby places it at risk of being lost through volatilisation or leaching. Recent results (Ball, 1977; Quin, 1977) suggest that these losses may be much greater than had previously been appreciated. Recently it has also become apparent that annual $\mathrm{N}$-inputs via symbiotic $\mathrm{N}$-fixation are somewhat less than had been previously thought (Hoglund et $a l$, 1979).The recognition that inputs may be lower than losses, suggests that intensive pastoral agriculture may deplete soil nitrogen. The restorative role that has previously been assigned to pastures is thus open to question. The dependency of nitrogen losses on stocking rate, led Field \& Ball (1982) to speculate whether high stocking rates could be sustained in New Zealand pastoral agriculture without increased use of fertiliser-N.

If agricultural systems are unbalanced, maximum or high levels of production cannot be maintained over long periods, although in the short term the depletion of soil nutrient reserves may be masked by the net release from soil organic matter. Maximum sustained animal production may be achieved by altering management to ensure that adequate litter is returned to the soil to maintain adequate levels of soil organic matter.

The study outlined in this paper aimed to determine the extent to which grazing intensity influences soil nitrogen and carbon balance, under a dryland ryegrasslwhite clover pasture. 
Table 1: YEAR TO YEAR VARIATION IN RAINFALL, MEAN PASTURE CONSUMPTION, N-FIXATION AND CHANGES IN SOIL CARBON AND NITROGEN.

\begin{tabular}{|c|c|c|c|}
\hline \multirow[b]{2}{*}{ Parameter } & \multicolumn{3}{|c|}{ Year } \\
\hline & $1978 / 79$ & 1979180 & 1980181 \\
\hline \multicolumn{4}{|l|}{ Rainfall (mm) } \\
\hline August-September & 227 & 162 & 62 \\
\hline August-April & 726 & 641 & 440 \\
\hline Live DM consumption ( $\mathrm{kg} / \mathrm{ha} / \mathrm{yr})$ & 6500 & 10200 & 7500 \\
\hline Mean post grazing DM $(\mathrm{kg} / \mathrm{ha})$ & 600 & 650 & 730 \\
\hline Mean nitrogen input' (kgN/ha/yr) & 165 & 74 & 39 \\
\hline \multicolumn{4}{|l|}{ Change in total soil carbon ( $\mathrm{kgC} / \mathrm{ha}$ ) } \\
\hline O-100 mm depth & 407 & 523 & -320 \\
\hline O- 200 mm depth' & -370 & 650 & -3200 \\
\hline \multicolumn{4}{|l|}{ Change in total soil nit. ( $\mathrm{kgN} / \mathrm{ha})$} \\
\hline O-100 mm depth & 110 & 59 & -64 \\
\hline $0.200 \mathrm{~mm}$ depth $^{3}$ & 93 & 30 & -213 \\
\hline Total nitrogen loss ( $\mathrm{kgN} / \mathrm{ha})$ & -72 & -44 & -252 \\
\hline
\end{tabular}

$1 \mathrm{~N}$-fixation + fertiliser- $\mathrm{N}$

2 Mean total carbon $=52500 \mathrm{kgClha}$

${ }^{3}$ Mean total nitrogen $=4700 \mathrm{kgN} / \mathrm{ha}$

\section{METHODS}

This trial was laid down in autumn 1978 on 1 year old ryegrass (Lolium perenne, Grasslands Nui) white clover (Trifolium repens, Grasslands Huia) pasture and ran for 3 years. The trial site was just north of Kirwee on a Chertsey silt loam.

Main experimental treatments (Table 2) were a range of grazing intensities achieved by varying ewe numbers relative to herbage on offer in each individually fenced treatment. Autumn nitrogen fertiliser $(40 \mathrm{~kg} \mathrm{~N})$ was applied to a treatment which was grazed with the same number of stock as the hard grazed treatment. A further 'variable' treatment involved a repeating sequence of skipping a grazing, a lax grazing and then a hard grazing. Accumulated dead material was removed by hard grazings of all treatments at every third grazing during the second and third years, coinciding with the hard grazing of the variable treatment.

Herbage DM was assessed before and after each grazing, by cutting quadrats to ground level with an electric shearing handpiece. N-fixation was measured twice during each regrowth using the methods of Hoglund \& Brock (1978). Soil volume weights, soil organic matter, carbon and nitrogen were measured annually on duplicate sets of 30 soil cores per treatment taken during early winter.

During the experiment the bulk density of the sampled soil horizons changed. Profile inversion caused by ploughing 2 years previously resulted in decreasing volume weights in the top $100 \mathrm{~mm}$ and increasing ones in the $100-200 \mathrm{~mm}$ depth When considered over the total surface $200 \mathrm{~mm}$ only comparatively minor changes occurred with time. In order to make unbiased comparisons between years and treatments, soil mineral weights were determined by subtracting the organic fraction, and then all soil nitrogen and carbon data were scaled to the mean mineral soil weight for each horizon (1.072 and $2.230 \times 10^{6} \mathrm{~kg} / \mathrm{ha}$ for top 100 and $200 \mathrm{~mm}$ respectively).

Least squares linear regression analyses was used to relate changes in soil nitrogen and carbon to the treatments imposed, 
Table 2: GRAZING INTENSITY TREATMENTS AND THEIR EFFECT ON DM CONSUMPTION AND N-FIXATION, AVERAGED OVER THREE YEARS.

\begin{tabular}{|c|c|c|c|}
\hline Parameter & $\begin{array}{l}\text { Mean post grazing } \\
\text { live DM } \\
\text { (kg/ha) }\end{array}$ & $\begin{array}{l}\text { Mean live DM } \\
\text { consumption } \\
\text { (kg/ha/yr) }\end{array}$ & $\begin{array}{c}\text { Mean N-fixation } \\
\text { (kgN/ha/yr) }\end{array}$ \\
\hline \multirow[t]{2}{*}{ Lax grazing ${ }^{*}$} & 900 & 7030 & 102 \\
\hline & 750 & 7730 & 107 \\
\hline \multirow{3}{*}{ intermediate: } & 730 & 7570 & 96 \\
\hline & 620 & 10180 & 96 \\
\hline & 550 & 9980 & 103 \\
\hline Hard grazing* & 470 & 9310 & 110 \\
\hline Hard $+\mathbf{N}^{2}$ & 570 & 10430 & $76+40^{\prime}$ \\
\hline Variable $^{2}$ & 1100 & 7950 & 102 \\
\hline
\end{tabular}

$1 \mathrm{~N}$-fixation + fertiliser- $\mathrm{N}$

2 Data for these treatments is mean of two replicates

\section{RESULTS AND DISCUSSIONS}

\section{Seasonal influences meaned over all treatments}

The third year was much drier than the previous two (Table 1), and only six grazings were possible compared with nine in the previous years. Mean live DM consumption was greatest in the second year when occasional hard grazings on all treatment were introduced, and least in the third, low rainfall year. Mean residual yields also reflected the change in grazing policy. Variation in mean nitrogen inputs reflected rainfall patterns, with clover yields and $\mathrm{N}$-fixation being particularly sensitive to early spring drought.

Net changes in soil carbon were positively related to live DM consumption, which on an annual basis can be considered to be broadly related to annual pasture growth. The loss of 3.2 tonnes of soil carbon in the third year represents $6.1 \%$ of the total soil carbon in that horizon, highlighting the sensitivity of soil organic matter balance to climatic fluctuations where soil moisture storage is low.

Changes in soil nitrogen levels are shown in Table 1. Nitrogen losses, calculated as the difference between soil- $\mathrm{N}$ change and $\mathrm{N}$-fixation, were least in the years of good pasture growth and greatest in the drought year. Assuming $4 \% \mathrm{~N}$ in the live DM, these nitrogen losses represent $11 \%$ of animal consumption in the best year and $84 \%$ in the poorest year. It is doubtful whether a loss of $252 \mathrm{kgN}$ could be repeated for many years as this must greatly deplete the available soil nitrogen pool.

\section{Grazing Intensity effects}

The grazing intensity treatments achieved mean live DM residuals ranging from 470 to $1100 \mathrm{~kg} / \mathrm{ha}$ (Table 2). The higher residuals on the $\mathrm{N}$-fertilised treatment reflect the policy of equating the stocking rates with that of the hard grazed control at most grazings. Annual DM consumption figures were not closely related to grazing intensity and tended to peak at residual DM of about $600 \mathrm{~kg} / \mathrm{ha}$. Nitrogen inputs were unaffected by treatment, except in that $\mathrm{N}$-fertiliser tended to replace $\mathrm{N}$-fixation.

Soil carbon and nitrogen accumulation were both positively related to post grazing residual yields (Figs. 1, 2), with relatively greater accumulation in the top 100 $\mathrm{mm}$ presumably reflecting the vertical imbalance caused by previous ploughing. During soil sampling a stony ridge was identified through one of the plots. Because losses were abnormally high, particulary of soil carbon, this replicate of the variable treatment was omitted from the overall analyses and the data have been circled in the figures. 


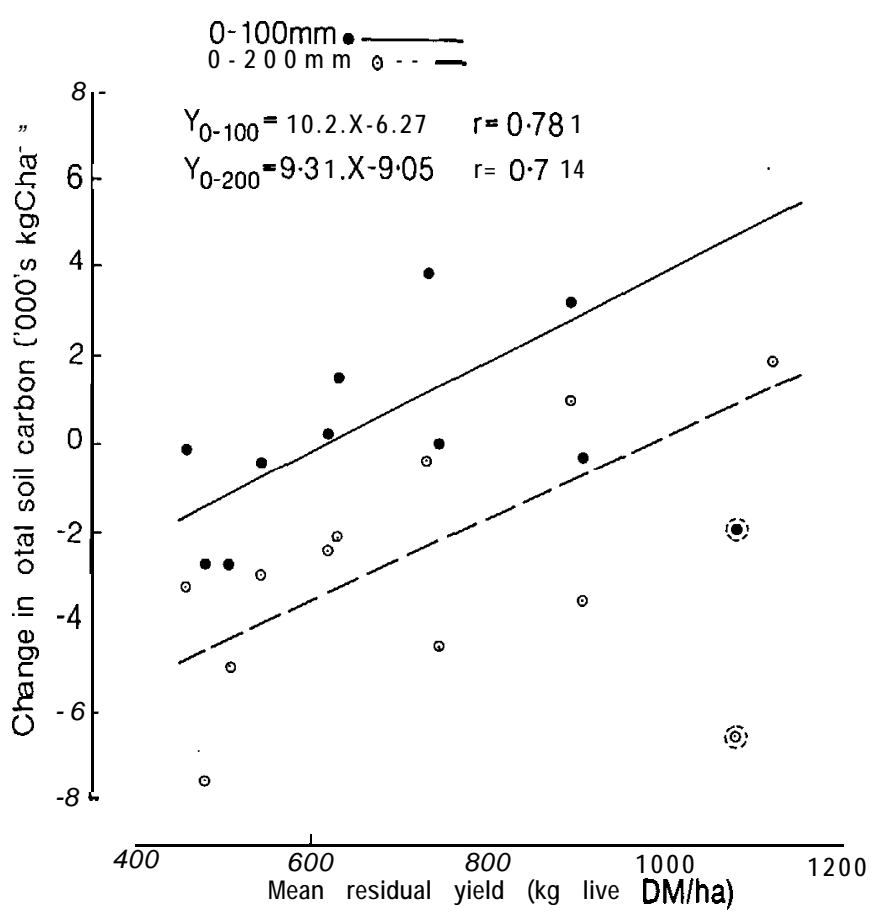

Figure 1: Total change in soil carbon over three years as a function of mean post grazing residual yields.

\section{$0-100 \mathrm{~mm}$
$0.200 \mathrm{~m} \mathrm{~m}$}

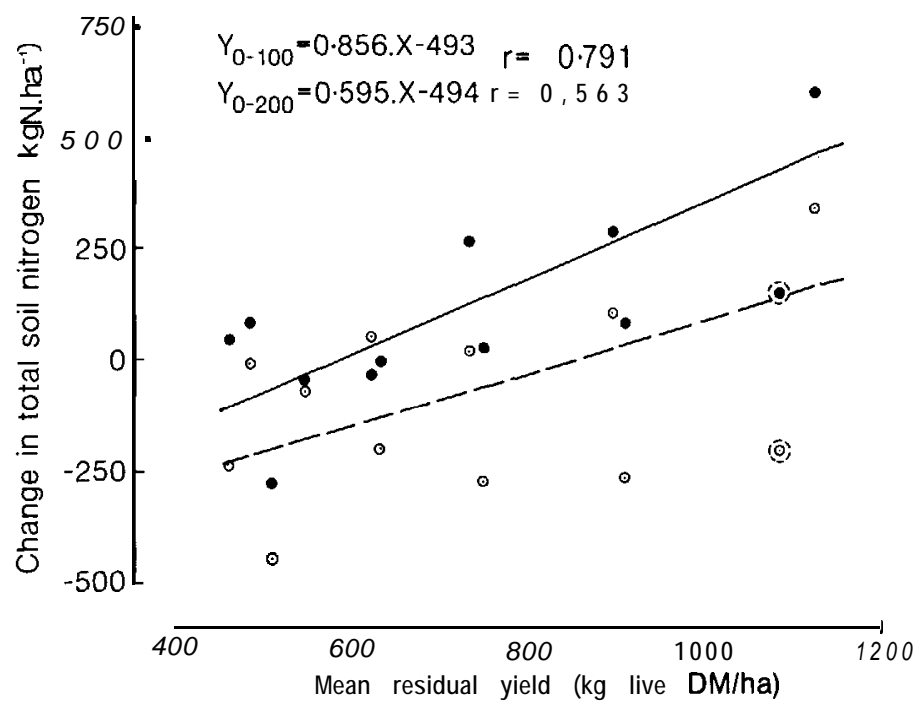

Figure 2: Total change in soil nitrogen over three years as a function of mean post grazing residual yields. 
The linear increase in soil carbon and nitrogen with increasing residual DM, emphasises the role of the litter pathway for feeding the soil organic matter pool, as apart from the hardest grazed treatments, root growth and decay was unlikely to have been significantly different among the remaining teatments. From the fitted relationships (Figs 1, 2), the rate of change in the top $100 \mathrm{~mm}$ was $1020 \mathrm{kgC/ha}$ and 86 $\mathrm{kgN} / \mathrm{ha}$ for every extra $100 \mathrm{~kg}$ residual DM. Over the full sampled depth this equates to a 6.5 tonne $\mathrm{C}$ and $450 \mathrm{kgN}$ difference between extreme grazing treatments. The hardest grazed treatments were unable to maintain carbon and nitrogen balance in this dryland environment, while the less intensely grazed treatments were able to accumulate nitrogen and carbon despite the large overall losses in the third year (Table 1). The difficulty of maintaining balance in dry environments is emphasised by the results from the plot on the stony ridge (circled in Figs. 1, 2).

Animal DM consumption was maximum at a grazing intensity just sufficient to maintain soil nitrogen and carbon balance in the top $100 \mathrm{~mm}$ of soil. Although perhaps only a coincidence, given the short term nature of this trial, this is nonetheless the expected long term result, in that it represents a compromise between maximising nitrogen availability for pasture growth and maintaining soil nitrogen balance. The effects of defoliation intensity on Leaf Area Index and sward structure have been emphasised in the past (Brougham, 1971; Harris, 1978), but an equally important long term consideration may be the need to maintain soil carbon

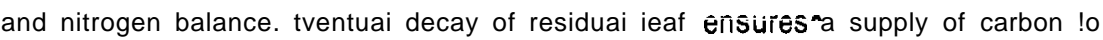
the soil, which in turn provides a substrate for stabilising mobile nitrogenous compounds. Additionally, rapid growth recovery by optimally grazed pastures quickly restores a sink for nitrogen after grazing, thereby minimising losses through volatilisation, leaching or both.

Notably in this study, maximum animal consumption per unit area was not coincident with lowest residuats, which emphasises the scope for good pasture management to overcome difficulties in maintaining soil nitrogen balance without the need to reduce stocking rates.

\section{ACKNOWLEDGEMENTS}

The experiment was conducted'on the property of $\mathrm{Mr} \mathrm{H}$. Williams, Kirwee. Field work and sample preparation were under the immediate supervision of $\mathrm{Mr} \mathrm{C}$. Pennell. Chemical analyses were carried out by the staff of the Grasslands Division analytical laboratory, Palmerston North.

\section{REFERENCES}

Ball, R. 1977. N.Z. Soil News 25: 171-183.

Brougham, R.W. 1971. Pro. N.Z. Grass/d Ass. 32: 137-144.

Field, T.R.O.; Ball, R, 1982. Ibid 43: 137-144

Harris, W. 1978. In: Plant Relations in Pastures. Ed., J.R. Wilson CSIRO, Australia. Hoglund, J.H.; Crush, J.R.; Brock, J.L.; Ball, R.; Carran, R.A. 1979. N.Z. J. exp. Agric. 7: 45-51.

Hoglund, J.H.; Brock, J.L. 1978. N.Z. J. agric. 21: 73-82.

Quin, B.F. 1977. N.Z. Soil News 25: (4). 